\title{
Aborting a Case of Living Donor Liver Transplantation Due to Pulmonary Hypertension: A Case Report
}

\author{
A Hilal*, G Zaki, N Fahmy and F Adeeb \\ Department of Anesthesia and Intensive Care, Ain Shams University, Egypt
}

Submission: February 25, 2017; Published: October 13,2017

*Corresponding author: A Hilal, Department of Anesthesia and Intensive Care, Ain Shams University, Cairo, Egypt, Tel: amr_hilal@yahoo.com

\begin{abstract}
Limited data suggest Liver Transplantation (LT) is considered high risk when moderate to severe Porto-Pulmonary Hypertension (POPH) (MPAP $>35 \mathrm{~mm} \mathrm{Hg}$ ) via right heart catheterization is documented. A literature review and multicenter data collection have documented up to $36 \%$ post-transplant in-hospital mortality in untreated patients when pre-LT MPAP exceeds moderate levels (>35 $\mathrm{mm} \mathrm{Hg)} \mathrm{[1].} \mathrm{In} \mathrm{the} \mathrm{early} \mathrm{experience}$ of POPH-LT case reporting, it was noted that $65 \%$ of all POPH cases were first diagnosed in the operating theater at the time of LT. Intraoperative death due to right heart failure was not infrequent [2].
\end{abstract}

Keywords: Liver transplantation; Pulmonary hypertension

\section{Case Report}

A Female patient 48 years old was evaluated preoperatively for fitness for living donor liver transplantation. The indication for transplantation was end stage liver disease caused by Hepatitis $C$ virus infection. Her BMI was 32.8. Her MELD score was 30 and Child score was C-10. Trans-thoracic Echocardiography showed a mild pericardial effusion, a mildly dilated RV and an estimated RVSP of 42mmHg for which she was receiving Sildenafil 25mg OD. Her medical record included 3 echocardiography reports with estimated RVSP 40, 37 and $42 \mathrm{mmHg}$ respectively.

On the day of surgery, before admission of the donor, she received a general anesthetic as per our protocol. A pulmonary artery catheter was inserted via the right internal jugular vein. Multiple ectopic beats and runs of ventricular tachycardia were noted during insertion.

Pressures were measured using a calibrated disposable transducer connected to a Drager monitor while the patient was ventilated to an end tidal CO2 of $30 \mathrm{mmHg}$ and FIO2 was 50\%. RAP (CVP) was around $25 \mathrm{mmHg}$. Pulmonary artery pressure was $45-$ 53/25-30mmHg. Pulmonary Capillary Wedge Pressure was 25-30 $\mathrm{mmHg}$ with constant large $\mathrm{V}$-waves in the wedge tracing possibly due to mitral regurge or due to LV dysfunction.

Pressures were observed for a period of 40 minutes. Changing FIO2 to $100 \%$ had a small effect in reducing PASP by about $5 \mathrm{mmHg}$.
Placing the patient in $15^{\circ}$ reverse Trendelenberg position and administration of Nitroglycerine infusion had no effect on these pressures.

We decided to abort the operation because of evidence of both right and left ventricular dysfunction. Persistent elevated RAP post-transplantation would result in decreased portal vein to IVC pressure gradient, congestion of the graft, poor graft perfusion and failure. There is an increased probability of increased pulmonary hypertension following reperfusion, which would precipitate RV failure.

\section{Discussion}

The idea that pulmonary artery catheterization is feasible and may be useful in the understanding of cardiac physiology and pathology was conceived for more than 80years ago. Its clinical application outside the catheterization laboratory, particularly in the diagnosis of critically ill patients, however, was delayed until floating balloon catheters were introduced in clinical practice. As expected after introduction of any recent procedure, device, or surgical and pharmacological therapeutic intervention, catheterization with the use of floating balloon catheters did not escape the phenomenon of overuse and misuse, which resulted in unwanted and serious complications. However, the knowledge gained in cardiac hemodynamic pathophysiology through 
the use of floating balloon catheters should not be dismissed. Furthermore, bedside hemodynamic studies have provided understanding of the hemodynamic correlates of abnormal clinical and echocardiographic findings in critically ill patients. A fairly higher personal experience with the use of floating balloon catheters, almost from the time of their introduction, and many observations about their use and abuse form the basis of this viewpoint [3].

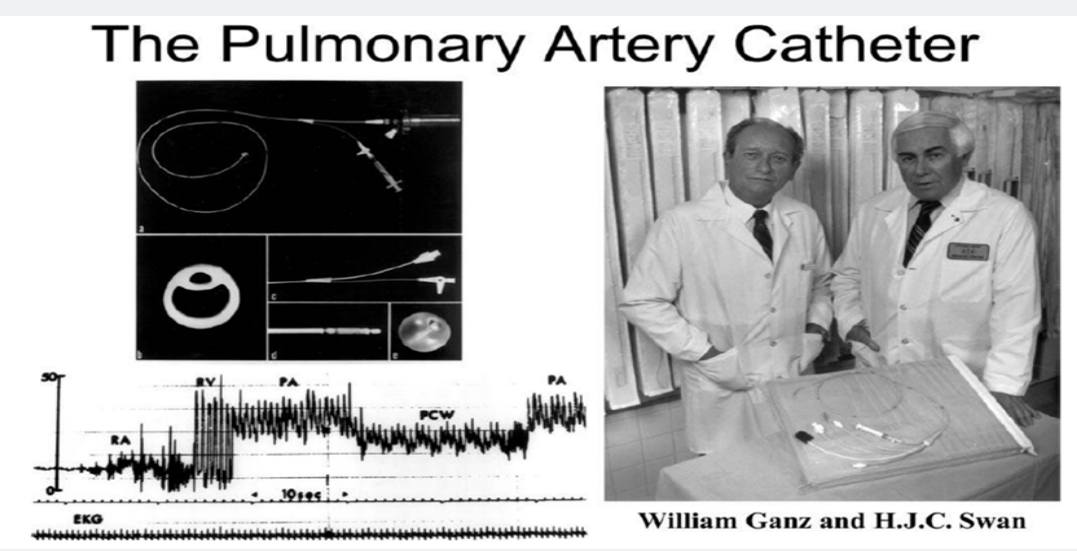

Figure 1: The double lumen balloon flotation catheter and its placement at the bedside without fluoroscopy and by monitoring intracardiac pressures. Photograph of Drs Swan and Ganz is also shown. RA indicates right atrium; RV: Right Ventricle; PCW: Pulmonary Capillary Wedge; PA: Pulmonary Artery. Figure courtesy of Dr Peter Ganz, Chief of Cardiology at San Francisco General Hospital, University of California, San Francisco.

In 1929, Dr Warner Forssmann first introduced a catheter into his own heart and established that right heart catheterization is feasible in humans. However, the catheter was advanced only into the right atrium [4]. Drs Andre Cournand and Dickinson Richards developed catheters that could be advanced into the pulmonary arteries and can be used to study the pathophysiology of congenital and acquired heart diseases. In 1956, Drs Forssmann, Cournand, and Richards received the Nobel Prize in medicine for their discoveries [5]. In 1964, Dr Bradley introduced the miniature diagnostic catheters that can be used in severely ill patients. In 1965, Dr Fife constructed self-guiding pulmonary artery catheters. In 1969, Drs Scheinman, Abbot, and Rapaport used a flow-directed right heart catheter for measurement of right heart pressures. However, balloon flotation flow-directed catheters that can be used at the bedside, without fluoroscopy, were introduced by Drs Swan and Ganz in 1970 (Figure 1) [6]. The floating balloon catheters, popularly known as "Swan-Ganz" catheters, were further developed for measuring cardiac output (by the thermodilution technique), for right atrial and right ventricular pacing, and for measuring right-sided pressures, including pulmonary capillary wedge pressure.

Pulmonary artery catheterization is necessary for the hemodynamic differential diagnosis of pulmonary arterial hypertension [7]. For example, presently no noninvasive tests are available for the accurate diagnosis of precapillary, postcapillary and mixed hemodynamic types of pulmonary arterial hypertension.

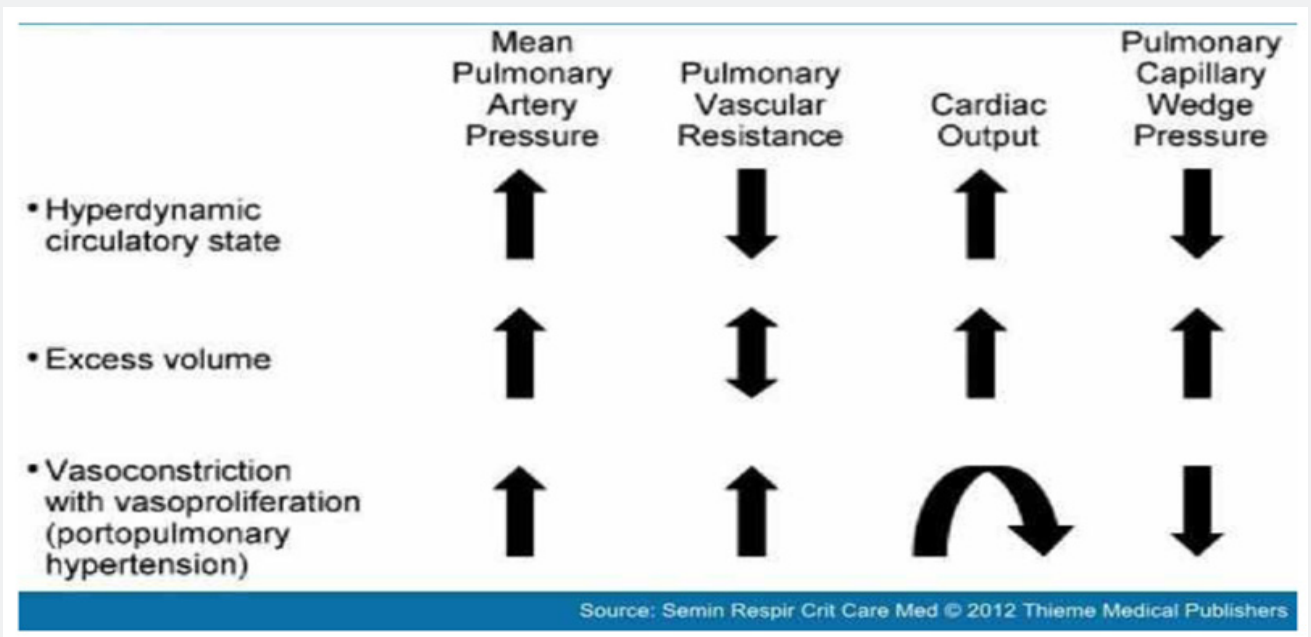

Figure 2: Pulmonary hemodynamic patterns documented by right heart catheterization in advanced liver disease. MPAP: Mean Pulmonary Artery Pressure; PCWP: Pulmonary Capillary Wedge Pressure; CO: Cardiac Output; PVR: Pulmonary Vascular Resistance 
POPH must be viewed within the spectrum of pulmonary hemodynamics thatoccurs as a consequence of portal hypertension from any cause. The correct characterization and interpretation of hemodynamics require Right Heart Catheterization (RHC) in that several reasons may exist for increased blood pressure within the pulmonary arteriovenous circulation as a consequence of portal hypertension (Figure 2). The hyperdynamic (high-flow) circulatory state, increased pulmonary venous volume/congestion, and vasoproliferation/vascular obstruction within the pulmonary arterial bed can each result in the general condition of Pulmonary Hypertension (PH) as defined by RHC measurement. A measured mean pulmonary artery pressure (MPAP) $>25 \mathrm{~mm}$ Hg defines $\mathrm{PH}$. The distinction between pulmonary artery hypertension and pulmonary venous hypertension requires further measurements. Specifically, such further classification requires measurement of pulmonary artery occlusion pressure and cardiac output, as well as the calculation of the transpulmonary gradient and pulmonary vascular resistance [8].

The usual hyper dynamic state in liver disease (driven by splanchnic bed vasodilation) is not associated with obstruction to pulmonary blood flow, and the calculated Pulmonary Vascular Resistance (PVR) is normal or low simply due to high cardiac output. Such a pulmonary hemodynamic pattern, associated with increased MPAP, has been documented in $\sim 35 \%$ of liver transplant candidates (measured by RHC) in a prospective Mayo Clinic study in which screening echocardiograms suggested pulmonary hypertension [9]. Such a hemodynamic status has no adverse implication for liver transplantation despite the documentation of MPAP that may be as high as 40 to $45 \mathrm{~mm} \mathrm{Hg}$ (with normal PVR).

Because up to $25 \%$ of patients with portal hypertension may have increased MPAP, PCWP > 15mm Hg, and markedly abnormal PVR $>240$ dynes s.cm-5, adequate classification of such patients has to be carefully considered [9]. Mayo Clinic investigators utilize the transpulmonary gradient calculation $(\mathrm{TPG}=\mathrm{MPAP}-$ PCWP) to infer whether clinically significant obstruction to flow is diagnosed and should be managed (if TPG > $12 \mathrm{~mm} \mathrm{Hg}$ ) with pulmonary vasodilator therapy in addition to added diuresis.

Every patient considered for LT is advised to have a screening transthoracic echocardiogram to assess for pulmonary hypertension and, if suggested, a confirmatory right heart catheterization [10].

At the time of operation, pulmonary artery measurements are again advised despite normal screening echocardiograms or management with pulmonary vasodilators because parameters may change over just a few months [11] if the MPAP $>50 \mathrm{~mm}$ $\mathrm{Hg}$ or the right ventricle is not satisfactory by echocardiography, the case is canceled. The development of acute right heart failure during reperfusion of the engrafted liver can be a major intraoperative event, potentially complicated by the occasional need for significant amounts of blood products to address intraoperative bleeding [11]. Even in normal situations, significant increases in $\mathrm{CO}$ can be acutely expected with reperfusion of the allograft. The scenario is potentially worse in the setting of an already compromised right ventricle due to increased pulmonary vascular resistance. Thus controlling pulmonary artery pressures with continuous intraoperative infusion of prostacyclin, inhaled nitric oxide, or infused milrinone during the transplant operation has been used to modify pulmonary hemodynamics during the operative management of POPH. The outcome in POPH if the LT attempt is aborted due to unacceptable pulmonary hemodynamics is poor.

Finally, the development of pulmonary artery hypertension de novo post-LT or following the resolution of hepatopulmonary syndrome is now well described [12]. The pathological correlates of this process are unknown and suggest a puzzling relationship between a diseased liver, replacement with a normal allograft, and subsequent pulmonary vascular remodeling or development to microemboli.

In our case, we concluded that despite pharmacological success in decreasing MPAP and PVR, along with improving right ventricular function, priority for LT in the presence of POPH remains problematic. LT should not be attempted unless significant hemodynamic improvement and improved right heart function can be documented; MELD exception is not a factor if living donor liver transplantation is considered in the setting of POPH.

\section{References}

1. Krowka MJ, Plevak DJ, Findlay JY, Rosen CB, Wiesner RH, et al. (2000) Pulmonary hemodynamics and perioperative cardiopulmonaryrelated mortality in patients with portopulmonary hypertension undergoing liver transplantation. Liver Transpl 6(4): 443-450.

2. Krowka MJ, Mandell MS, Ramsay MA, Kawut SM, Fallon MB, et al. (2004) Hepatopulmonary syndrome and portopulmonary hypertension: a report of the multicenter liver transplant database. Liver Transpl 10(2): 174-182.

3. Chatterjee K (2009) The Swan-Ganz Catheters: Past, Present, and Future. A viewpoint. Circulation 119(1): 147-152.

4. Forssmann W (1929) Die Sondierung des rechten Herzens. Klinische Wochenschr 8(45): 2085-2087.

5. Bradley RD (1964) Diagnostic right-heart catheterization with miniature catheters in severely ill patients. Lancet 2(7366): 941-942.

6. Swan HJ, Ganz W, Forrester J, Marcus H, Diamond G, et al. (1970) Catheterization of the heart in man with the use of a flow-directed balloon-tipped catheter. N Enql J Med 283(9): 447-451.

7. Chatterjee K, De Marco T, Alpert JS (2002) Pulmonary hypertension: hemodynamic diagnosis and management. Arch Intern Med 162(17): 1925-1933.

8. Rodríguez-Roisin R, KrowkaMJ, Hervé P, Fallon MB (2004) ERS Task Force Pulmonary-Hepatic Vascular Disorders (PHD) Scientific Committee; Pulmonary-hepatic vascular disorders (PHD). Eur Respir J 24(5): 861-880.

9. Krowka MJ, Swanson KL, Frantz RP, McGoon MD, wiesner RH (2006) Portopulmonary hypertension: results from a 10-year screening algorithm. Hepatology 44(6): 1502-1510. 
10. Murray KF, Carithers RL, AASLD (2005) AASLD practice guidelines: evaluation of the patient for liver transplantation. Hepatology 41(6) 1407-1432.

11. Ramsay M (2010) Portopulmonary hypertension and right heart failure in patients with cirrhosis. Curr Opin Anaesthesiol 23(2): 145150.
12. Koch DG, Caplan M, Reuben A (2009) Pulmonary hypertension after liver transplantation: case presentation and review of the literature. Liver Transpl 15(4): 407-412.
This work is licensed under Creative Commons Attribution 4.0 Licens

DOI:10.19080/IJOPRS.2017.02.555585
Your next submission with Juniper Publishers will reach you the below assets

- Quality Editorial service

- Swift Peer Review

- Reprints availability

- E-prints Service

- Manuscript Podcast for convenient understanding

- Global attainment for your research

- Manuscript accessibility in different formats ( Pdf, E-pub, Full Text, Audio)

- Unceasing customer service

Track the below URL for one-step submission https://juniperpublishers.com/online-submission.php 